\title{
I-123 Metaiodobenzylguanidine Cardiac Scintigraphy in Patients with an Implanted Permanent Pacemaker
}

\author{
Akio Nakata, M.D., Satoshi Hirota, M.D., \\ Hiroshi Tsujt, M.D., \\ and Eisuke TAKaZaKura, M.D.
}

\section{SumMaRY}

Tl scintigraphic abnormalities have been reported in patients with an implanted permanent pacemaker, but little is known about the MIBG scintigraphic findings in such patients. This study was performed to assess the MIBG scintigraphic findings in patients with an implanted permanent pacemaker, and to test the hypothesis that imaging characteristics of MIBG scintigraphy differ according to its mode. Twelve patients 4 men and 8 women, mean age: $72.4 \pm 9.5$ years), who had undergone the implantation of a permanent pacemaker for bradyarrhythmias, underwent MIBG scintigraphy, The patients were divided into VVI pacemaker and DDD pacemaker groups. The tomograms were divided into nine segments and the MIBG defect in each segment scored on a scale ranging from 0 (normal uptake) to 3 (no uptake). Total MIBG defect scores were generated by summing the scores for the nine segments in each patient. MIBG scintigraphic abnormalities were found in ten of the twelve patients. The six patients with the VVI pacemaker manifested MIBG scintigraphic abnormalities. These MIBG scintigraphic abnormalities were observed in all segments, particularly in the posterior segments. The mean total defect score of the VVI group was higher than that of the DDD group $(14.8 \pm 9.8$ vs $3.0 \pm 3.5$, respectively $p<0.05)$. Therefore, we conclude that despite several limitations of the study, MIBG scintigraphic abnormalities occur in patients with implanted permanent pacemakers, and that such abnormalities are more prominent with the VVI than DDD pacemaker. (Jpn Heart J 36: 583-591, 1995)

Key words: VVI pacemaker DDD pacemaker Sympathetic nervous system Holter ECG Echocardiography

I -123 Metaiodobenzylguanidine (MIBG), an analogue of the adrenergic blocking agent guanethidine, is taken up in the presynaptic storage vesicles of the adrenergic nerve as norepinephrine. Thus MIBG scintigraphy has been performed to evaluate the sympathetic nervous system, ${ }^{1-4)}$ including the assessment

From the Department of Internal Medicine, Kurobe Municipal Hospital, Kurobe, Japan.

Address for correspondence: Akio Nakata, M.D., Department of Internal Medicine, Kurobe Municipal

Hospital, 1108-1 Mikkaichi, Kurobe, Toyama 938, Japan.

Received for publication February 8, 1995.

Accepted June 12, 1995 
of cardiac sympathetic nerve denervation and reinnervation following acute myocardial infarction, ${ }^{5)}$ valvular heart disease, ${ }^{6)}$ and idiopathic cardiomyopathy. ${ }^{4,7)}$ However, little is known about MIBG scintigraphic findings in patients with implanted permanent pacemakers. Artificial pacing causes hemodynamic changes, particularly in the VVI mode, which may influence the cardiac sympathetic innervation. This study was performed to assess MIBG scintigraphic findings in patients with an implanted permanent pacemaker and to test the hypothesis that the imaging characteristics of MIBG differ according to the pacing mode.

\section{Methods}

Subjects: Twelve patients ( 4 men and 8 women, mean age: $72.4 \pm 9.5$ years) with implanted permanent pacemakers for bradyarrhythmias were enrolled in this study. None of these patients had experienced prior myocardial infarction or angina pectoris. Underlying heart diseases included sick sinus syndrome $(n=5)$, atrioventricular block $(n=3)$ and bradycardiac atrial fibrillation $(n=4)$. There were two patients with diabetes mellitus in each group. The patients were divided into VVI and DDD pacemaker groups (Table I).

I-123 MIBG myosardial scintigraphy: Cardiac I-123 MIBG scintigraphy was performed in all patients. A dose of $3 \mathrm{mCi}$ of commercially available I-123 MIBG (Daiichi Isotope, Tokyo, Japan) was administered intravenously. To allow for clearance of extraneuronal tissue uptake, cardiac SPECT images were acquired 4 hours following injection using a one-head gamma camera (Maxicamera $400 \mathrm{AC}$, General Electric, Milwaukee, WI, USA). The data were reconstructed by filtered-back projection (Star, General Electric). Oblique tomographic slices

Table I. Clinical Characteristics of Study Patients

\begin{tabular}{rcllll}
\hline Case No. & Age (yrs) & Sex & Mode & Underlying arrhythmias & DM \\
\hline 1 & 78 & male & VVI & af bradycardia & $(+)$ \\
2 & 75 & male & VVI & af bradycardia & $(+)$ \\
3 & 64 & male & VVI & af bradycardia & $(-)$ \\
4 & 80 & female & VVI & SSS & $(-)$ \\
5 & 81 & female & VVI & SSS & $(-)$ \\
6 & 67 & female & VVI & af bradycardia & $(-)$ \\
7 & 68 & female & DDD & AV block & $(-)$ \\
8 & 67 & female & DDD & SSS & $(-)$ \\
9 & 50 & female & DDD & SSS & $(-)$ \\
10 & 77 & male & DDD & SSS & $(+)$ \\
11 & 80 & female & DDD & AV block & $(+)$ \\
12 & 82 & female & DDD & AV block & $(-)$ \\
\hline
\end{tabular}

af = atrial fibrillation; SSS = sick sinus syndrome; $\mathrm{AV}$ block = atrioventricular block; DM = diabetes mellitus. 


\section{${ }^{123}$ I-MIBG uptake}

Short axis

Proximal Distal

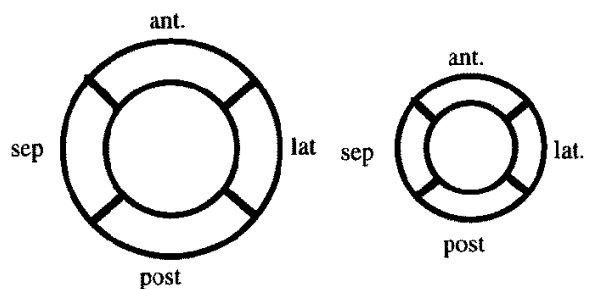

Long axis

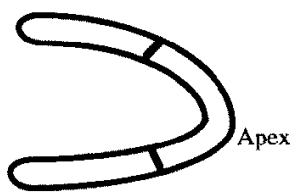

Figure 1. Line drawings depicting the configuration of the vertical long-axis, apical short axis and basal short axis sections. ant $=$ anterior; lat $=$ lateral; post $=$ posterior; sep $=$ septal.

in the short and vertical long axes were computed and displayed.

I-123 MIBG analysis: The tomograms were divided into nine segments for semiqualitative interpretation. Two short-axis slices (one each from the apex and base) were each divided into four evenly spaced regions. The apex was interpreted using the vertical long-axis view (Figure 1). For semiquantitative assessment, the images were scored by the visual estimation of the extent of the MIBG defect in each of the nine segments, using a scale ranging from 0 (normal uptake) to 3 (no uptake). Total MIBG defect scores were generated by summing the scores of the nine segments for each patient.

Thallium-201 myocardial scintigraphy: In eight patients, myocardial imaging using $2 \mathrm{mCi}$ of Tl-20l chroride was performed at rest. Scintigrams were obtained and analyzed as MIBG myocardial scintigraphy.

Holter 24-hour EGG: All patients underwent Holter 24-hour electrocardiography (ECG). Holter recording and analysis were performed using a DMC4100 system (Nihon Kohden, Tokyo, Japan). Percentages of the ventricular (V) pacing beat to the 24-hour beats were calculated to determine the $\mathrm{V}$ pacing rate. Ultrasonic echocardiography: All patients underwent ultrasonic echocardiographic studies using SSD-9000 (ALOKA, Tokyo, Japan) and the left ventricular ejection fraction (LVEF) was evaluated in each patient by the method of Teichholtz. 
Statistical analysis: Data are expressed as the mean \pm SD. The nonparametric Mann-Whitney $U$ test was used to test for significant differences in the baseline patient characteristics and I-123 MIBG defect scores. The Student's paired $t$ test was used to compare the total defect scores of MIBG and Tl-201. A value of $p<0.05$ was considered significant.

\section{Results}

The patient characteristics are shown in Table I. The mean ages did not differ between the VVI and DDD groups ( $74.2 \pm 7.1$ years vs. $70.7 \pm 11.9$ years). The sex ( 3 men: 3 women vs. 1 man: 5 women), duration ( $5.7 \pm 4.2$ years vs. $3.8 \pm 2.8$ years), LVEF $(52.5 \pm 14.3 \%$ vs. $63.6 \pm 8.2 \%)$, and $\mathrm{V}$ pacing rate $(49.2 \pm 33.7 \%$ vs. $41.2 \pm 46.8 \%)$ also did not significantly differ between these respective groups (Table II).

Table II. Comparison of Baseline Clinical Data between the VVI and DDD Groups

\begin{tabular}{lccl}
\hline & $\begin{array}{c}\text { VVI } \\
(n=6)\end{array}$ & $\begin{array}{c}\text { DDD } \\
(n=6)\end{array}$ & $\begin{array}{c}p \\
\text { Value }\end{array}$ \\
\hline Age (yrs) & $74.2 \pm 7.1$ & $70.7 \pm 11.9$ & 0.8723 \\
Sex (male/female) & $(3 / 3)$ & $(1 / 5)$ & 0.303 \\
Duration (yrs) & $5.7 \pm 4.2$ & $3.8 \pm 2.8$ & 0.5196 \\
V pacing rate $(\%)$ & $49.2 \pm 33.7$ & $41.2 \pm 46.8$ & 0.5159 \\
LVEF (\%) & $52.5 \pm 14.3$ & $63.6 \pm 8.2$ & 0.2281 \\
\hline
\end{tabular}

LVEF = left ventricular ejection fraction; $V=$ ventricular. Values are presented as the mean \pm SD.

Table III. MIBG Defect Scores of all Patients

\begin{tabular}{|c|c|c|c|c|c|c|c|c|c|c|}
\hline \multirow{3}{*}{$\begin{array}{c}\text { Case } \\
\text { No. }\end{array}$} & \multicolumn{8}{|c|}{ MIBG defect score } & \multirow[b]{3}{*}{ apex } & \multirow[b]{3}{*}{ total } \\
\hline & \multicolumn{4}{|c|}{ Proximal } & \multicolumn{4}{|c|}{ Distal } & & \\
\hline & ant & lat & post & sep & ant & lat & post & sep & & \\
\hline 1 & 3 & 3 & 3 & 3 & 3 & 3 & 3 & 3 & 3 & 27 \\
\hline 2 & 3 & 3 & 3 & 3 & 3 & 3 & 3 & 3 & 3 & 27 \\
\hline 3 & 1 & 0 & 2 & 1 & 2 & 0 & 3 & 0 & 3 & 12 \\
\hline 4 & 0 & 0 & 1 & 0 & 1 & 0 & 1 & 0 & 1 & 4 \\
\hline 5 & 0 & 0 & 2 & 2 & 0 & 0 & 2 & 1 & 2 & 9 \\
\hline 6 & 0 & 0 & 2 & 1 & 1 & 0 & 2 & 2 & 2 & 10 \\
\hline 7 & 0 & 2 & 2 & 0 & 0 & 2 & 2 & 0 & 1 & 9 \\
\hline 8 & 0 & 0 & 1 & 0 & 0 & 0 & 1 & 0 & 0 & 2 \\
\hline 9 & 0 & 0 & 0 & 0 & 0 & 0 & 0 & 0 & 0 & 0 \\
\hline 10 & 0 & 0 & 0 & 0 & 0 & 0 & 0 & 0 & 0 & 0 \\
\hline 11 & 0 & 0 & 1 & 0 & 0 & 0 & 1 & 0 & 0 & 1 \\
\hline 12 & 0 & 0 & 2 & 0 & 0 & 0 & 2 & 0 & 1 & 5 \\
\hline
\end{tabular}

ant $=$ anterior; lat $=$ lateral; post $=$ posterior; sep $=$ septal 


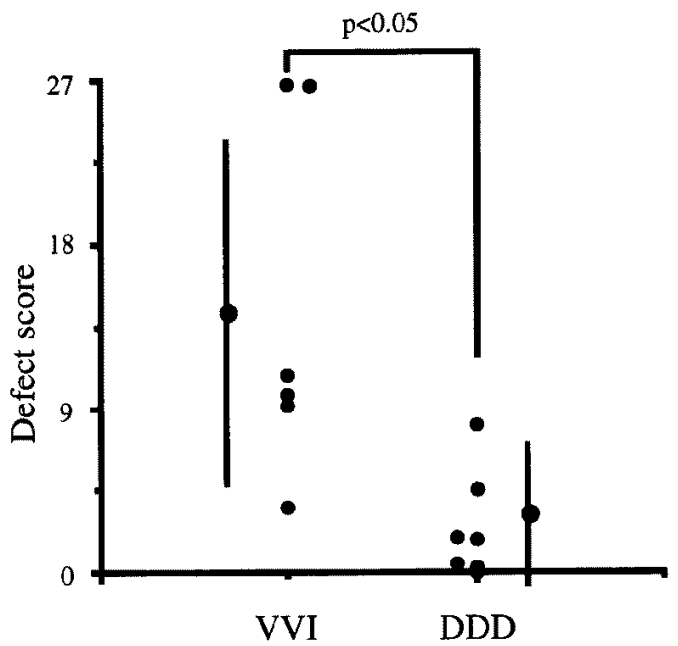

Figure 2. Comparison of the total MIBG defect scores between the VVI and DDD groups. Bars indicate SD.

Table IV. Thallium Defect Scores

\begin{tabular}{|c|c|c|c|c|c|c|c|c|c|c|}
\hline \multirow{3}{*}{$\begin{array}{l}\text { Case } \\
\text { No. }\end{array}$} & \multicolumn{10}{|c|}{ Thallium defect score } \\
\hline & \multicolumn{4}{|c|}{ Proximal } & \multicolumn{4}{|c|}{ Distal } & \multirow[b]{2}{*}{ apex } & \multirow[b]{2}{*}{ total } \\
\hline & ant & lat & post & sep & ant & lat & post & sep & & \\
\hline 1 & 0 & 0 & 2 & 2 & 0 & 0 & 1 & 2 & 3 & 10 \\
\hline 2 & 0 & 0 & 1 & 0 & 1 & 0 & 2 & 0 & 3 & 7 \\
\hline 4 & 0 & 0 & 0 & 0 & 0 & 0 & 0 & 0 & 0 & 0 \\
\hline 6 & 0 & 0 & 0 & 0 & 0 & 0 & 0 & 0 & 0 & 0 \\
\hline 7 & 0 & 0 & 0 & 0 & 0 & 0 & 0 & 0 & 0 & 0 \\
\hline 9 & 0 & 0 & 0 & 0 & 0 & 0 & 0 & 0 & 0 & 0 \\
\hline 10 & 0 & 0 & 0 & 0 & 0 & 0 & 0 & 0 & 0 & 0 \\
\hline 12 & 0 & 0 & 0 & 2 & 0 & 0 & 0 & 1 & 0 & 3 \\
\hline
\end{tabular}

ant $=$ anterior $;$ lat $=$ lateral; post $=$ posterior; $\operatorname{sep}=$ septal

Table III shows the MIBG scintigraphic findings in each case. MIBG scintigraphic abnormalities were found in ten of the twelve patients. The six patients with VVI pacemakers all manifested MIBG scintigraphic abnormalities. These MIBG scintigraphic abnormalities were observed in all segments, particularly in the posterior segment. A comparison of the total MIBG defect score between the VVI and DDD groups is shown in Figure 2. The mean total defect score of the VVI group was higher than that of the DDD group (14.8 $\pm 9.8 \mathrm{vs}$. $3.0 \pm 3.5$, respectively, $p<0.05$ ).

$\mathrm{Tl}$ scintigraphic abnormalities were noted in three of the eight patients (Table IV). In each patient, the total $\mathrm{Tl}$ defect score was lower than the MIBG defect score (2.5 \pm 3.9 vs. $10.3 \pm 11.0$, respectively, $p<0.05)$ (Figure 3 ). 


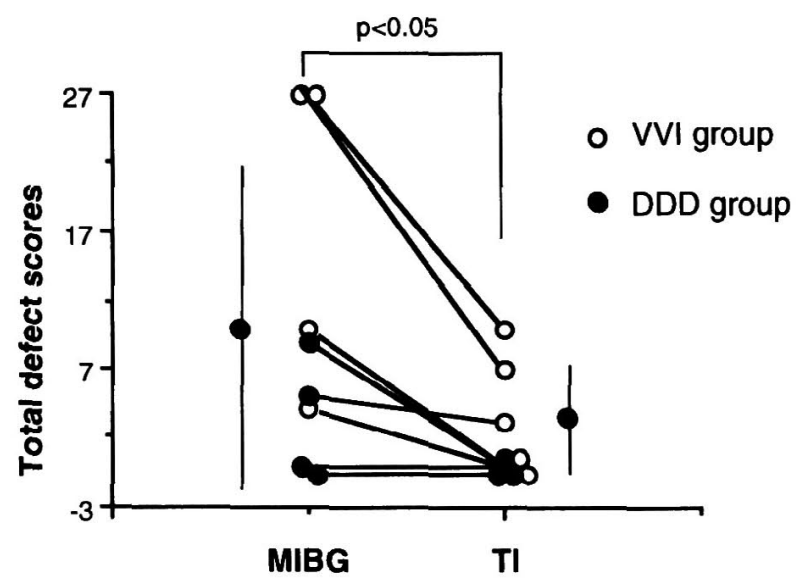

Figure 3. Comparison of the total MIBG and Tl defect scores. Individual data are connected. Bars indicate SD.

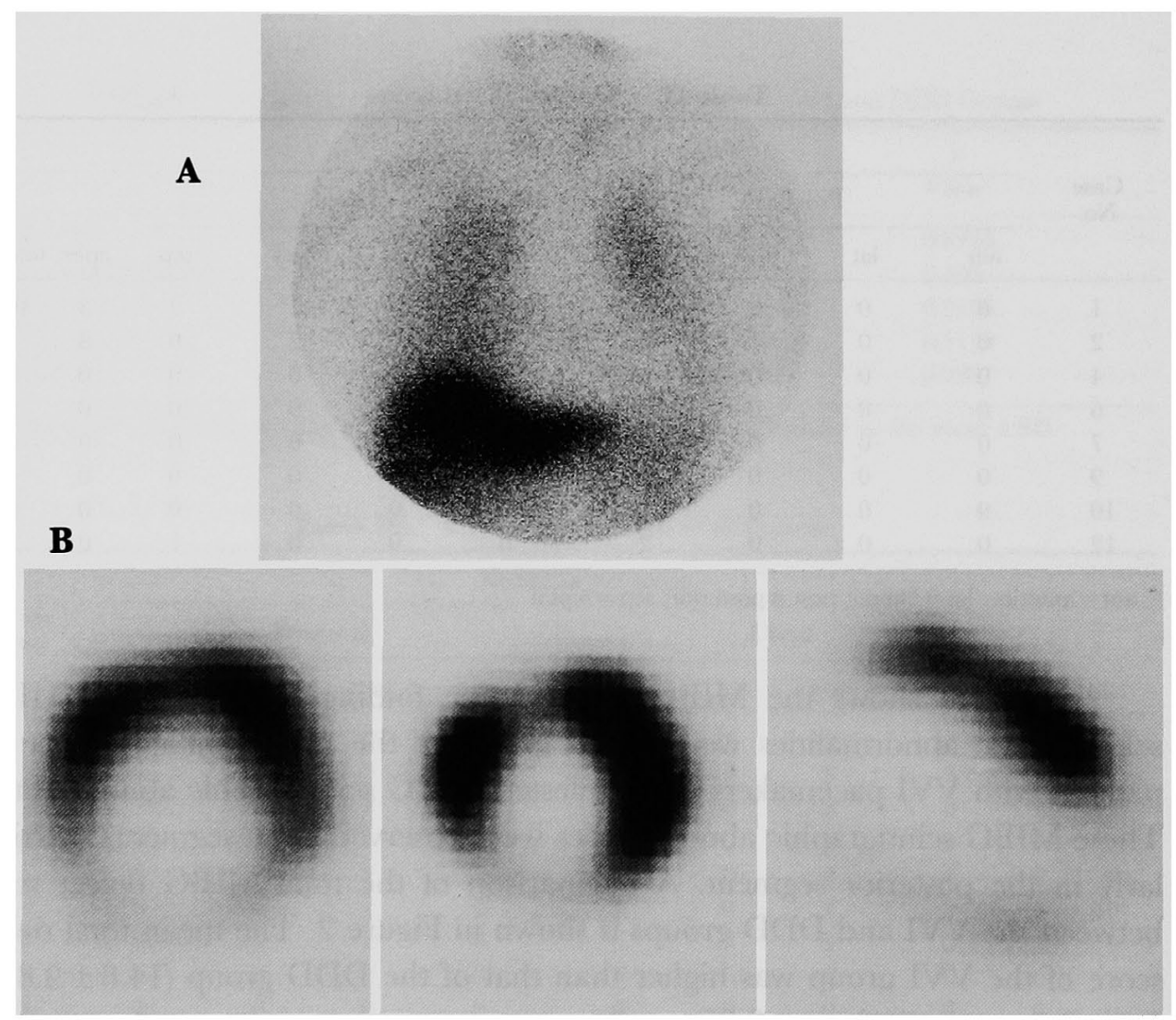

Figure 4. A representative example (case No. 2). There is an absence of I-123 MIBG localization and the total MIBG defect score was calculated as 27. (A) Tl-201 myocardial scintigraphy revealed low uptake in a distal site of the anterior wall, posterior wall, proximal site of the posterior wall and defect in the apex. The total Tl defect score was calculated as 7. (B) 
Representative images of a patient in the VVI group are shown in Figure 4. There is no visible cardiac uptake and the total MIBG defect score was calculated as 27 (A). Tl myocardial scintigraphy revealed low uptake in the distal site of the anterior wall, posterior wall, proximal site of the posterior wall and a defect in the apex. The total $\mathrm{Tl}$ defect score was calculated as 7 (B).

\section{Discussion}

In this study, patients with an implanted permanent pacemaker showed various degrees of reduction in left ventricular MIGB activity. This reduction was more prominent in the VVI than the DDD group. In this limited study of eight patients, thallium scintigraphic abnormalities were observed in three patients. However, the MIBG scintigraphic abnormalities were greater than the Tl scintigraphic abnormalities.

The mechanism for the reduction in MIBG activity in patients with implanted permanent pacemakers was not evaluated in this study. $\mathrm{Tl}$ scintigraphic abnormalities have been reported mainly in the posteroseptal, posteroinferior, and apical regions in patients with a permanent pacemaker. ${ }^{8)}$ Defects detected by Tl scintigraphy can express either reduced perfusion or a disturbance of the Tl201 uptake process. In this study, MIBG scintigraphic defects were observed even in the normal perfusion segments of Tl. The mechanism of MIBG scintigraphic abnormalities may differ from that of $\mathrm{Tl}$ scintigraphy.

MIBG is a guanethidine analogue originally described by Wieland et al. ${ }^{97}$ In 1981 , a study revealed that MIBG is a norepinephrine storage analogue ${ }^{11}$, and another documented normal MIBG cardiac imaging in humans. ${ }^{10)}$

The explanation of MIBG scintigraphic abnormalities is only speculative. One possible explanation is related to the increased sympathetic nervous system activity during ventricular pacing. This activity has been reported to increase more in patients with a VVI than DDD pacemaker. Maintenance of atrioventricular synchrony during DDD pacing has been associated with lower levels of cardiac sympathetic activity. Increased sympathetic activity in patients with a VVI pacemaker may result in the down-regulation of cardiac sympathetic nervous system activity.

Cardiac pacing is well-established in the management of patients with severe disorders of impulse initiation and transmission in the cardiac conduction system. The prognosis and quality of life are markedly improved in most patients. However, $12-31 \%$ of patients suffer sudden death within months or years of pacemaker implantation. ${ }^{11-13)}$ DDD pacing has been shown to possess comparative hemodynamic advantages over VVI pacing, and patient survival is significantly better with DDD pacing, regardless of the indications for pacing. ${ }^{14,15)}$ In 
cases of generalized autonomic neuropathy, either idiopathic, diabetic and/or Shy-Drager syndrome, MIBG scintigraphy demonstrates diffuse patterns of low uptake or defects, ${ }^{16,17)}$ and abnormal uptake of MIBG scintigraphy is reported to be related to sudden cardiac death. MIBG scintigraphic abnormalities in patients with an implanted pacemaker also may be related to sudden cardiac death.

Study limitations: In this study, the underlying arrhythmias differed between the two groups and four patients with diabetes mellitus were included. Although MIBG scintigraphic abnormalities in patients with diabetes mellitus have been reported, the same number of patients with this condition were included in each group and no patient manifested autonomic neuropathy. Therefore, we believe that the differences in the total MIBG defect scores between the two groups reflect a true difference between the pacing modes. However, the examination of more patients will be needed to confirm these preliminary observations.

\section{Conclusion}

MIBG scintigraphic abnormalities were seen in patients with an implanted permanent pacemaker and these abnormalities were more prominent with the VI than DDD pacemaker.

\section{References}

1. Wieland DM, Brown LE, Rogers WL, Worthington $\mathrm{KC}, \mathrm{Wu}$, Clinthorne NH, Otto CA, Swanson DP, Beierwaltes WH: Myocardial imaging with a radioiodinated norepinephrine storage analog. J Nucl Med 22: 22, 1981

2. Tobes MC, Jaques S, Wieland DM, Sisson JC: Effect of uptake-one inhibitors on the uptake of norepinephrine and meta iodobenzylguanidine. J Nucl Med 26: 897, 1985

3. Dae MW, O'Connell W, Botvinick EH, Ahearn T, Yee E, Huberty JP, Mori H, Chin MC, Hattner RS, Herre JM, Munoz L: Scintigraphic assessment of regional cardiac adrenergic innervation. Circulation 79: 634,1989

4. Henderson EB, Kahn JK, Corbett JR, Jansen DE, Pippin JJ, Kulkarni P, Ugolini V, Akers MS, Hansen C, Buja LM, Parkey RW, Willerson JT: Abnormal I-123 Metajodobenzylguanidine myocardial washout and distribution may reflect myocardial adrenergic derangement in patients with congestive cardiomyopathy. Circulation 78: 1192, 1988

5. Minardo JD, Tuli MM, Mock BH, Weiner RE, Pride HP, Wellman HN, Zipes DP: Scintigraphic and electrophysiological evidence of canine myocardial sympathetic denervation and reinnervation produced by myocardial infarction or phenol application. Circulation 78: 1008, 1988

6. Fagret D, Wolf JE, Vanzetto G, Borrel E: Myocardial uptake of metaiodobenzylguanidine in patients with left ventricular hypertrophy secondary to valvular aortic stenosis. J Nucl Med 34: 57, 1993

7. Schofer J, Spielmann R, Schuchert A, Weber K, Schlüter M: Iodine-123 meta-iodobenzylguanidine scintigraphy; a noninvasive method to demonstrate myocardial adrenergic nervous system disintegrity in patients with idiopathic dilated cardiomyopathy. J Am Coll Cardiol 12: 1252, 1988

8. Hirzel HO, Senn M, Neusch K, Buettner C, Pfeiffer A, Hess OM, Krayenbuel HP: Thallium-201 scintigraphy in complete left bundle branch block. Am J Cardiol 53: 764, 1984

9. Wieland DM, Wu J,Brown LE, Mangner TJ, Swanson DP, Beierwaltes WH: Radiolabeled adrenergic neuron-blocking agents; adrenomedullary imaging with $\left[{ }^{[31} \mathrm{I}\right]$ iodobenzylguanidine. J Nucl Med 21: 349, 1980 
10. Kline RG, Swanson DP, Wieland DM, Thrall JH, Gross MD, Pitt B, Beierwaltes WH: Myocardial imaging in man with I-123 meta-iodobenzylguanidine. J Nucl Med 22: 129, 1981

11. Siddons H: Deaths in long-term paced pacients. Br Heart J 36: 1201, 1974

12. Breivik K, Ohm OJ: Myopotential inhibition of unipolar QRS-inhibited (VVT) pacemakers, assessed by ambulatory Holter monitoring of the electrocardiogram. PACE 3: 470, 1980

13. Simon $A B$, Janz $N$ : Symptomatic bradyarrhythmias in the adult; natural history following ventricular pacemaker implantation. PACE 5: 372, 1982

14. Hesselson AB, Parsonnet V, Bernstein AD, Bonavita GJ: Deleterious effects of long-term single-chamber ventricular pacing in patients with sick sinus syndrome: the hidden benefits of dual-chamber pacing. J Am Coll Cardiol 19: 1542, 1992

15. Alpert MA, Curtis J, Sanfelippo JF, Flaker GC, Walls JT, Mukerji V, Villarreal D, Katti SK, Madigan NP, Krol RB: Comparative survival after permanent ventricular and dual chamber pacing for patients with chronic high degree atrioventricular block with and without preexistent congestive heart failure. $J$ Am Coll Cardiol 7: 925, 1986

16. Nakajyo M, Shimabukuro K, Miyaji N, Shimada J, Shirono K, Sakata H, Yoshimura H, Yonekura R, Shinohara S: Rapid clearance of iodine-131 MIBG from the heart and liver of patients with adrenergic dysfunction and pheochromocytoma. J Nucl Med 26: 357, 1985

17. Sisson JC, Shapiro B, Meyers L, Mallette S, Mangner TJ, Wieland DM, Glowniak JV, Sherman P, Bcicrwaltes WH: Metaiodobenzylguanidine to map scintigraphically the adrenergic nervous system in man. J Nucl Med 28: 1625, 1987 